\title{
Using Augmented Reality to Enhance and Engage Students in Learning Mathematics
}

\author{
Wen-Hung Chao \\ Department of Digital Media Design, \\ Asia University, Taiwan, R.O.C. \\ Rong-Chi Chang \\ Department of Technology Crime Investigation, \\ Taiwan Police College, Taiwan, R.O.C.
}

\begin{abstract}
The study shall apply Augmented Reality (AR) technique to develop Math learning App. The learners shall apply the mobile device to scan the cards and convert the 2D floor plan into 3D objects. By manipulating virtual 3D objects, students can understand the 3D composition from different perspectives. By applying the decomposition or combinated functions of the Math learning App, students can further understand the calculation way of Volume. The study confers the learning outcomes of the school children before and after applying AR Math App through the introduction and experiment design of the teaching site, and discusses the difference between Math highaccomplished school children and ordinary children by way of digital learning. Through the ways of achievement tests, questionnaire and teachers' and childrents' interviews, the study understands the learning effects and experiencing of AR Math App. The experiment's result indicates that students can accept the AR Math learning App developed by the institute and it can also initiate their interests in learning. The result before and after studying indicates that the learning effects have significantly promoted. The result of teachers' interviews indicate that the application of this digital teaching materials and interactive experience model has effectively enhanced the students understanding the concept of Volume and 3D composition.
\end{abstract}

Keywords: e-learning, virtual reality, geometry, interactive learning, mathematics

\section{INTRODUCTION}

Math is considered as a foundation of the development in science, technology and thought, and Geometric and Spatial capabilities help us to identify the positions, sizes, and shapes of the objects in our living. Geometry and Spatial Competence Training can be used to construct virtual spaces by operations like combining, pushing and stacking, and measuring so as to increase the 2D and 3D spatial cognition. Wheately (1990) found that spatial abilities and visual images played an extremely important role in the thinking and learning of Math, and he considered that there were some degrees of correlation between spatial capabilities and Math learning.

Math learning attaches importance on a logical structure of gradual and orderly process, the training of traditional Math teaching and deductive Logic, and the formula and definition composed by forcing memorial abstract symbols. Due to spoon-fed learning, students usually lack interest in Math. Researches indicate that the more confident Math students are, the better their Math performance will be. Young students generally understand the importance of Math, but fearing Math still exists in their mind. Making studnets curious about Math and happy to 
learn can lay a good foundation of their Math, and lead to a good result in science or ideological development in the future.

The Ministry of Education's 9-year Integrated Curriculum (2008), Math learning is divided into 'Number \& Quantity', 'Graphics \& Space', 'Statistics \& Probability' and 'Algebra'. Among them, 'Graphics \& Space' is not easy to learn, in addition to the calculations of 'Number \& Quantity,' there is a sense of space learning experience. Students' thinking in 3D space is weaker either in the direct operation of teaching tools or indirect learning from the floor plan, and their thinking converting from 2D graphics to 3D space is more difficult. Teachers spend more time in teaching those than the other units. They need to use a variety of supporting materials to make students fully understand the unit of Volume.

To enhance learning by applying Information Communication Technology (ICT) is considered as one of the key attributes in the modern society. The scope of digital learning includes lifelong learning of the public and the enterprise's massive needs in digital learning (Prensky, 2001). Due to the development of digital technology, interactive media has attracted the attention of all circles. The prevalence of mobile devices today allows the teaching tools to be extended on mobile phones and game-learning via App. And Augmented Reality (AR) technology can attach the virtual world to the real space, integrated with human sensory nerve, and it is not necessary to simulate imagination, and can make it present instantly. AR has been widely used in game media, magazine books, and navigation systems; in the field of teaching, it is also gradually widely used such as Arithmetic, Spatial Transformation and courses understanding and so on. Teachers can create supplementary teaching tools through the features of digital technology so that they can own an extra useful teaching tool and learners can also be more interested and their learning impressions can be deepened consequently.

Therefore, in order to understand the benefits of applying digital technology in 'Geometry' unit learning, the study has designed an interactive AR Math learning APP targeting on fifth-grade elementary school students. The purpose of developing this teaching materials is mainly to arouse students' motivation for self-studying so as to assist the learning of 'Plane' and '3D shape.' Through the interactive operation mode, they can understand the relationship between the cubic composition and cubic structure. In order to discuss the differences in learning effectiveness between traditional Math learning methods and the interactive digital teaching materials as well as to observe the introduction of information technology into teaching sites and the students' attitude of acceptance and application.

\section{LITERATURE REVIEW}

In recent years, in order to present a more natural way of operation, the study has adopted interactive behaviors like voices and gestures. For example, in the study environment by applying Virtual Reality (VR) technology, students are able to interact by using different devices and virtual teaching materials, which indicates the potentiality of information technology development (Cai, Wang, \& Chiang, 2014). AR, a variant of VR, collocates with virtual systems and real tools to achieve a platform of mixed reality so as to increase learner's experience in learning. In the mixed reality, the application of human-computer interaction can enhance learner's learning interest and learning (Hsieh \& Lee, 2008).

The application of AR has three characteristics: integrating reality with virtual world, instant interacting and 3D entities and virtual objects. (Azuma, 1997) The teaching experience provided by AR includes supporting unobtrusive interactions between real and virtual environments, simulating touchable interface of object operations, and is also able to smoothly transform real and virtual worlds. (Park, SB, Jung, JJ, \& You, E., 2015) Unlike other computer 
interaction technologies, AR allows users to leave from the real world and just focus on the screen, which can enhance learners' cognition of the actual environment. As a result, AR can help to enhance students' motivation and interest in learning and to support teaching and learning in an educational setting, and has considerable potentiality in technology. (MartínGutiérrez, Fabiani, Benesova, Meneses, \& Mora, 2015)

The rapid development of technology products like VR, AR and mobile devices has given users different experiences in the manipulation of technology products. The application of IT to education is also an important topic to be discussed. Due to the change of human-computer interaction between computers and users from traditional keyboard and mouse control to image-based interface and sensory control, experts and researchers in all fields attach great importance to user experience issues. (Jetter \& Gerken, 2006; Mahlke, 2005) The products, system or service developed by the designer need to improve the content of the interface and enhance user's experience by observing the feedback provided by users after interacting with the product through the steps of user's experience satisfaction (Hsu et al., 2012; Su et al., 2014). In particular, the development of emerging technologies being applied to the field of education is even more necessary to understand the mastery of science and technology and the usefulness of the system through the experience of users.

3D is an innovative digital application that presents objects in a visual scene after being threedimensional, allowing users to actually observe and operate them. And the virtual objects can be designed into a control trigger event to achieve immediate interactive effect. In comparison with the traditional real interface, AR can provide users more presence experience. Therefore, AR technology is regarded as a promising teaching material among many teaching materials.

AR technology provides users with a seamless interface integrated with the real world. AR technology is widely used in the fields of engineering, flight training, environmental science, medication and education. The application of AR's fast detection technology and computing capability with the characteristics of mobile devices or cell-phones integrating with environments (objects like buildings, signs or natural landscapes), one can experience an ubiquitous scene of being engaged in a real life.

A great number of studies show that AR technology has been applied to K-12 to higher education and has greatly improved educational outcomes, (Chiu, DeJaegher, \& Chao, 2015) including Engineering Education (Behzadan, Dong \& Kamat, 2015), Natural Science, (Tsai et al., 2012) History Studies, Design and Mathematics Education, etc. That AR is applied to assist high school students in studying design is found that it helps to improve students' ability of independent thinking, creativity and critical analysis, which has potentiality of teaching. (Bower et al., 2014) Estapa and Nadolny (2015) made an experiment and found that the assistance of AR in high school Math learning can improve students' performance and motivation to learn mathematics. Study by Taharim, Lokman, Hanesh and Aziz (2016) indicated that AR technology could help to enhance the interest of history students in junior high school. The function of the simulated situation of AR technology helps to clarify abstract concepts. Martín-Gutiérrez et al., (2015) applied AR to simulate 3D real-world operation of electrical engineering equipments to assist learners to self-learn, which helps to effectively connect theory with practice. Delgado-Kloos et al., (2015) applied basic principles of augmented reality simulating electricity experiments and found that it could effectively enhance students' motivation and learning outcomes.

Besides science, AR environment can also be applied to arts. Cheng \& Tsai (2013) developed a library-based AR system that significantly improved academic performance did help to 
improve learners' motivation and willingness to learn. In the Visual Arts course, Di Serio, Ibáñez and Kloos (2013) discussed the impact of the AR system on students' learning motivation. Experiments showed that AR had a positive effect on the learning motivation of junior middle school students. In addition, there are many AR applications in situational exploration or experience of related learning experiments. For example, Chang, Hou, Pan, Sung \& Chang (2015) applied AR mobile navigation system to assist college students to guide cultural monuments. Ke \& Hsu (2015) applied AR integrated with mobile learning system to assist pre-service teachers in teaching science content and technology study. Cheng \& Tsai (2016) applied AR experiment of picture books and e-book reading to confer parent-child interaction and sharing activities, and also found that the results were significantly better than those of traditional learning. It was also helpful to deepen and apply the teaching content and to conclude effective strategies of teaching reformation.

\section{DEVELOPMENT OF INTERACTIVE MATH TEACHING MATERIALS}

A study indicated (Liu \& Tasi, 2013), among Math subjects of elementary school students, they have difficulty in studying the category of 'Graphics and Space'. Therefore, the study has designed contents of teaching materials based on 'Pillar' and 'Volume' units of Math in the elementary schools. The design of teaching materials is researched and developed jointly by two Math teachers, who have more than 10-year teaching experiences in Math.

Such an interactive AR Math App was developed with the Unity 3D IDE and Vuforia SDK. Unity 3D is a cross-platform game engine for single-user games like Windows, MacOS and Linux, or games for iOS and Android mobile devices. Unity 3D has a handy module on digital scenes, 3D objects and logic procedure of programming design, which makes it ideal for creating AR or VR applications.

The study has developed an AR Math App that is interactively guided. Students can download and install the software through mobile devices. This software interface has designed interactive operation instructions, which allow students to learn Math by hands, and can increase their studying interest. Figure 1 and Table 1 show a description of the App interactive functions. For the different interactive operations for different learning units, for instance the math Pillar unit illustrated in Figure 2.

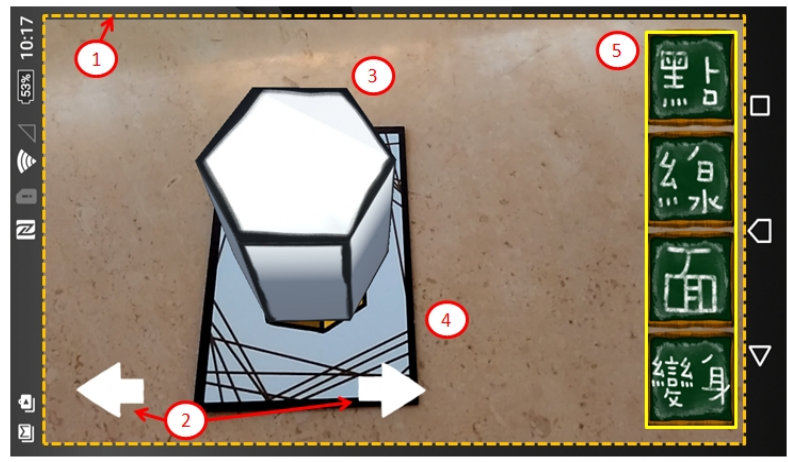

Fig. 1. The interactive Math app.

Table 1. App interface function descriptions

\begin{tabular}{cl}
\hline No. & Function description \\
\hline 1 & AR Interactive window \\
2 & Rotate \\
3 & 3D object \\
4 & AR learning card \\
5 & Interactive function \\
\hline
\end{tabular}



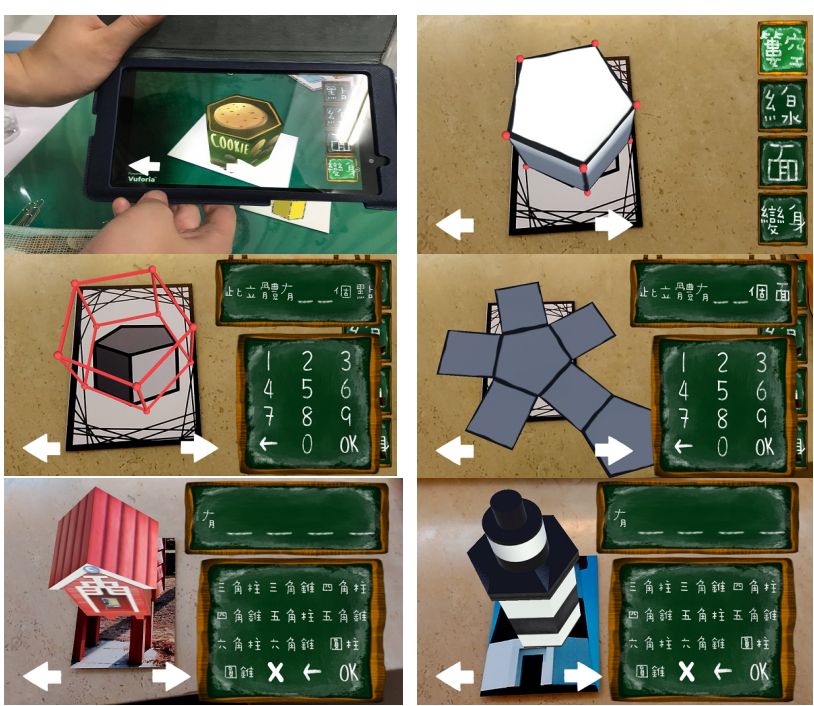

Fig. 2. Multimedia effects of the AR Math learning app

METHODS AND EXPERIMENTAL

The purpose of the study is to discuss the introduction of digital leaning materials on 'Pillar' unit of Math for $6^{\text {th }}$-grade elementary school students. Through the interactive learning model and the application of information technology, students can be guided to acquire knowledge of Pillar, Geometry and 3D Composition. And then it discusses AR Math learning App for students' studying achievement, motivation and influence of acceptance of science and technology as well as to understand students' feelings and opinions about the overall curriculum.

\section{Participants}

Participants in the study were two classes of $6^{\text {th }}$-grade students of an elementary school with a total of 63 students (see Table 2), one of which was an experimental team; and the other class was a control team. Both classes were taught by the same Math teacher. The content of the course was selected to study Math 'Pillar' as the subject of study and a 4-week teaching experiment ( 2 hours a week) was conducted to understand its effectiveness.

Table 2. Demographic characteristics of the participants.

\begin{tabular}{lccc}
\hline & Experimental group & Control group & Total \\
\hline Boys & 17 & 15 & 32 \\
Girls & 15 & 16 & 31 \\
Total & 32 & 31 & 63 \\
\hline
\end{tabular}

\section{Experimental process}

Before the course stated, two teams of students needed to take a pre-test and pre-study questionnaire to ensure that two teams of students for the 'Pillar' had no significant difference in prior knowledge.

When the activity started, the experimental team attended an AR App instructional course to ensure the team students know how to operate the App. After that, two teams of students respectively conducted different kinds of teaching activities. The experimental team was learning Math by an interactive AR Math App, and the control team was equipped with computers and video information to be integrated with Math learning activities. After the activities of two teams were completed, both post-test and post-study questionnaires, the experimental flow chart is shown in Fig. 2. The questionnaire was measured before and after the experiment to see if learners' motivation before and after the experiment was affected. In addition, the study questionnaire also includes a science and technology acceptance questionnaire. 


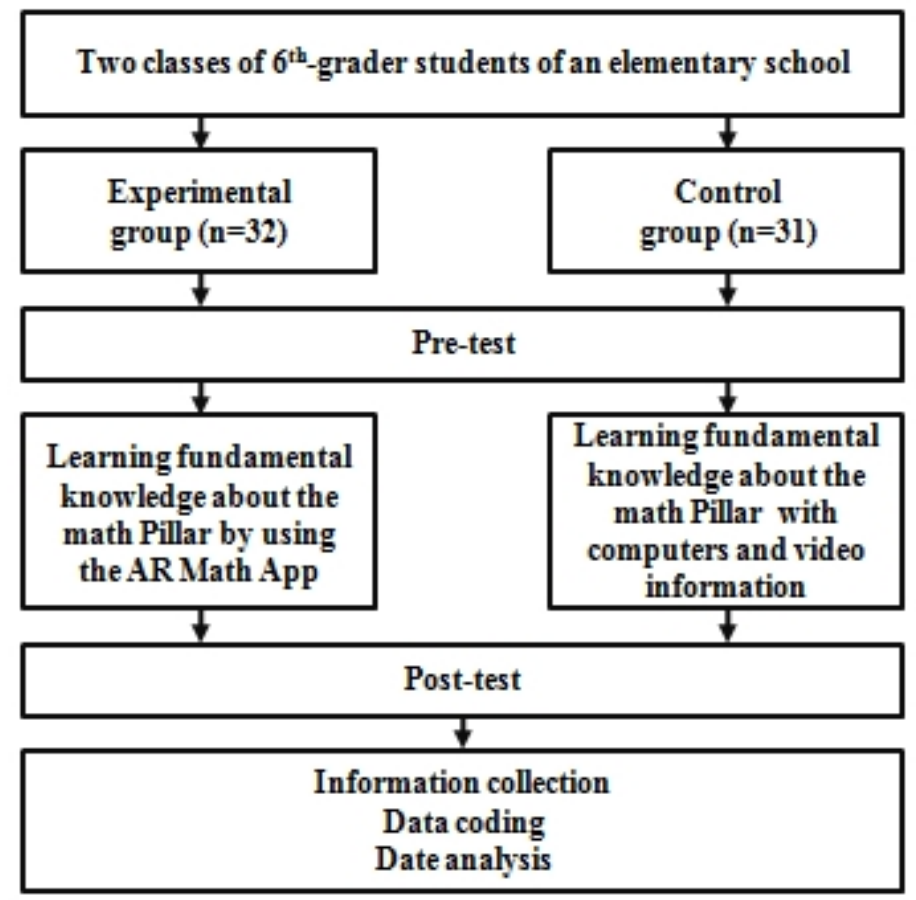

Fig. 2. Experimental procedure

\section{Research Tools}

The research tools of the experiment include learning achievement test and questionnaire. Questionnaire was used to test students' motivation for learning and science and technology acceptance. The content of the achievement test consisted of two teachers who had more than ten years in teaching experiences. Pretest is to test the students' basic 3D common sense. The test content had 10 questions with a total of 100 points. With pre-testing, how students understood the degree of knowledge of Pillar could be learned in advance. Post-testing had 10 questions with a total of 100 points. The topic focused on the students' knowledge quiz and graphic concept of 3D, pillar and 3D composition to understand whether it could help students successfully distinguish the relevance among these three after they studied by way of digital learning.

Science and technology acceptance assessment forms were filled out after the experiment. The science and technology acceptance assessment adopted by the study was reedited from the Science and Technology Acceptance Assessment scales by Chu, Hwang, Tsai and Tseng (2010). The questionnaire included two aspects of 'Cognitive Usefulness' and 'Cognitive Easy-to-use', with a total of 13 Question ( $\alpha=.910)$, using Likert's 5-point scale. 'Cognitive usefulness' mainly investigated whether users' learning of learning tools was helpful for learning. Cognitive Easyto-use was used to understand if learners could easily use the learning tools.

\section{Learning Achievement Analysis}

\section{EXPERIMENTAL RESULTS}

In order to understand whether the prepared knowledge of two teams of students was the same before learning activity, independent samples t test was performed on the pre-test scores to evaluate the Math-based ability of two teams before the experiment. According to the statistical results of the pre-test of Math, the average score of the experimental team was 67.21 points, and the average score of the control team was 67.41 points. There was no significant difference between the experimental team and the control team $(\mathrm{t}=0.425, p>0.1)$, Which was not statistically significant. It showed that students in the experimental team and the control team had the same basic Mathematical abilities before the experiment. 
To compare the learning outcomes between two teams in the experimental team and the control team, whether there was a significant difference and covariates were used as the covariance (ANCOVA) to analyze the post-test results. In order to meet the basic assumptions of the covariance analysis, two teams of results were used to test

First, test of homogeneity of regression coefficients showed that the regression coefficients were homogenous $(\mathrm{F}=0.526, p=.470>.05)$, indicating the relationship between the covariance (pretest scores) and the dependent variables (post-test scores) It would not be different due to the different treatment level of the independent variable, which was in line with the assumption of homogeneity of the regression coefficient in the covariate set, so that covariance analysis could be carried out.

As it can be shown from Table 3, after excluding the influence of the covariance (pre-test score) on the dependent test items (post-test score), there was a significant difference between two test scores after the Math test $(\mathrm{F}=4.348, p=.039<.05)$. The average score of students in experimental team was 75.86 and the standard deviation was 14.83 . The average score of students in control team was 69.75 and the standard deviation was 20.32. In other words, the interactive AR App math learning had better leaning effects than traditional information integrated with Math learning, and had achieved a statistically significant level.

Table 3. The ANCOVA test results for learning achievement from post-test of the two groups.

\begin{tabular}{lcccccc}
\hline & $\mathrm{N}$ & $\mathrm{M}$ & S.D. & Adjusted Mean & S.E. & $\mathrm{F}$ \\
\hline Experimental group & 32 & 75.86 & 14.83 & 76.01 & 2.14 & $4.348^{*}$ \\
Control group & 31 & 69.75 & 20.32 & 69.73 & 2.07 & \\
\hline
\end{tabular}

$* p<.05$

\section{Math Study Motivation Analysis}

In order to discuss if the interactive AR learning could improve the Math learning motivation of the experimental team, the researchers analyzed the scores before and after the Math learning motivation assessment scale of two teams to understand the effect of different strategies of teaching activities on students' learning motivation influences.

First, the independent sample t test was conducted for the total score of the total questions of the learning motivation assessment scale (Pickett-Like 5-point scale) before the teaching activity. The average score of the control team was 4.27 points and the standard deviation was 1.06. The average score of the experimental team was 4.28; the standard deviation is 1.17 . The results of $t$ test showed that there was no significant difference between two teams in motivation before teaching. ( $t=0.054, p=.957>.05)$.

After the experiment ended, two teams were given a motivation questionnaire after the study, and single-factor covariates (ANCOVA) were used to analyze their scores.

First, a test of homogeneity of regression coefficients was implemented and it showed that the regression coefficients were homogenous $(F=2.921, p=.09>.05)$, indicating the relationship between the covariates (pretest scores) and the dependent variables. (post-test scores) It was not different due to the different treatment level of the independent variables, which was in line with the assumption of homogeneity of the regression coefficients in the covariate.

Then, the covariate analysis was implemented and it was shown from Table 4. After excluding the influence of the covariate (pre-motivation questionnaire) on the dependent variable (postmotivation questionnaire), there was a significant difference between two teams in terms of motivation scores after Math. $(F=8.80, p=.004<.01)$. In other words, interactive AR App 
learning had a better learning motivation than traditional information integrated with Math learning and reached a significant level in statistics.

Table 4. The ANCOVA test results for study motivation from post-test of the two groups.

\begin{tabular}{lcccccc}
\hline & $\mathrm{N}$ & $\mathrm{M}$ & S.D. & Adjusted Mean & S.E. & $\mathrm{F}$ \\
\hline Experimental group & 32 & 4.85 & 092 & 4.86 & 0.106 & $8.80^{* *}$ \\
Control group & 31 & 4.41 & 1.12 & 4.42 & 0.105 & \\
\hline
\end{tabular}

** $p<.01$

\section{Technology Acceptance Analysis}

In order to understand the status of science technology acceptance status of the experimental team and the control team after implementing Math digital learning. The researchers analyzed the scores of science technology acceptance scales in two teams to understand the impact of different strategies of learning activities on the acceptability of science technology. The questions included 12 questions for 'Cognitive Usefulness' and 'Cognitive Easy-to-use'. The questions were scored by using a Likert 4-point scale. The independent sample t test was used to analyze the scores of science technology acceptability. The experimental team was learning AR App while the experimental team was learning in traditional digital way. As it can be seen from Table 5, the science technology acceptance of the experimental team was higher than that of the control team with significant levels $(p=.00<.001)$, that was, AR App Learning allowed students to rate technology acceptance higher than normal digital learning.

Table 5. The t-test scores for technology acceptance of the two groups.

\begin{tabular}{lcccc}
\hline & $\mathrm{N}$ & $\mathrm{M}$ & $\mathrm{S} . \mathrm{D}$. & $\mathrm{t}$ \\
\hline Experimental group & 32 & 3.31 & 0.63 & $4.08^{* * *}$ \\
Control group & 31 & 2.85 & 0.57 & \\
\hline$* * * p<.001$ & & & &
\end{tabular}

\section{CONCLUSION}

In school's curriculum, some abstract knowledge can not help students to understand and learn effectively in a traditional way of teaching. However, the development of AR App can provide us with different degrees of interactivity and presentation of information, and further help learners to learn meaningfully. In recent years, there are more and more researches and applications in this area. Applying AR App as a teaching tool not only can create a learning environment, but also promote learners' active participation, problem solving and meaningful learning. However, learning through the assistance of technology does not necessarily improve students' learning effectiveness. Technology being introduced must also be accompanied by a good teaching strategy to help students to learn. The result of the study has found that learning content of 'Pillar' unit by applying AR Math App can help to improve students' learning outcomes and learning motivation through interactive operations and changes of 3D space. In addition, students who apply AR App learning can also significantly accept science technology more than the control team, which is consistent with the results of researches in the past.

\section{ACKNOWLEDGMENT}

This work was supported in part by the Ministry of Science and Technology of the Republic of China under contract 105-2511-S-261-001-MY2. 


\section{References}

Azuma, R. T. (1997). A survey of augmented reality. Presence, 6(4), 355-385.

Cai, S., Wang, X., \& Chiang, F.-K. (2014). A case study of augmented reality simulation system application in a chemistry course. Computers in Human Behavior, 37, 31-40.

Cheng, K.H.; Tsai, C.C., (2013). Affordances of Augmented Reality in Science Learning: Suggestions for FutureResearch. Journal of Science Education and Technology, 22:449-462.

Hsieh, M.-C., \& Lee, J.-S. (2008). AR marker capacity increasing for kindergarten Englishlearning. Retrieved from http://www.iaeng.org/publication/IMECS2008/IMECS2008_pp663-666.pdf

Mahlke, S. (2005). Understanding users' experience of interaction. Paper presented at the Proceedings of the 2005annual conference on European association of cognitive ergonomics. (University of Athens), 251-25

Marc Prensky, (2001) "Digital Natives, Digital Immigrants Part 1", On the Horizon, 9(5):1-6, https://doi.org/10.1108/10748120110424816

Martín-Gutiérrez, J., Fabiani, P., Benesova, W., Meneses, M. D., \& Mora, C. E. (2015). Augmented reality to promote collaborative and autonomous learning in higher education. Computers in Human Behavior, 51, 752-761. doi: 10.1016/j.chb.2014.11.093

Ministry of Education, General Guidelines of Grade 1-9 Curriculum of Elementary and Junior High School Education, 2003.

Jetter, Hans-Christian \& Gerken, Jens. (2006). A Simplified Model of User Experience for Practical Application. First publ. in: NordiCHI 2006, Oslo: The 2nd COST294-MAUSE International Open Workshop "User eXperience Towards a unified view." (2007), 106-111.

Hsu, C.-C., Chen, H.-C., Su, Y.-N., Huang, K.-K., \& Huang, Y.-M. (2012). Developing a reading concentration monitoring system by applying an artificial bee colony algorithm to E-Books in an intelligent classroom. Sensors, 12(10), 14158-14178.

Su, Y.-N., Hsu, C.-C., Chen, H.-C., Huang, K.-K., \& Huang, Y.-M. (2014). Developing a sensor-based learning concentration detection system. Engineering Computations, 31(2), 216-230.

Chiu, J. L., DeJaegher, C., \& Chao, J. (2015). The Effects of Augmented Virtual Science Laboratories on Middle School Students' Understanding of Gas Properties. Computers \& Education, 85, 59-73.

Bower, M., Howe, C., McCredie, N., Robinson, A., \& Grover, D. (2014). Augmented reality in education-cases, places and potentials. Educational Media International, 51(1), 1-15. doi: 10.1080/09523987.2014.889400

Taharim, N. F., Lokman, A. M., Hanesh, A., \& Aziz, A. A. (2016). Feasibility study on the readiness, suitability and acceptance of M-learning AR in learning history. Proceedings of the Applied Mathematics in Science and Engineering Proceedings 1705, 020009. doi: 10.1063/1.4940257

Estapa, Anne; Nadolny, Larysa (2015), The Effect of an Augmented Reality Enhanced Mathematics Lesson on Student Achievement and Motivation, Journal of STEM Education: Innovations and Research, 16(3):40-48.

Delgado Kloos, C., Muñoz-Merino, P. J., Alario-Hoyos, C., Ayres, I. E., \& Fernández Panadero, C. (2015). Mixing and Blending MOOC Technologies with Face-to-Face Pedagogies. IEEE Global Engineering Education Conference (EDUCON), 967-971.

Di Serio, A., Ibanez, M. B., \& Kloos, C. D. (2013). Impact of an augmented reality system on students' motivation for a visual art course. Computers \& Education, 68, 586-596.

Chang, Y. L., Hou, H. T., Pan, C. Y., Sung, Y. T., \& Chang, K. E. (2015). Apply an augmented reality in a mobile guidance to increase sense of place for heritage places. Journal of Educational Technology \& Society, 18(2), 166178.

Ke, F., \& Hsu, Y. C. (2015). Mobile augmented-reality artifact creation as a component of mobile computersupported collaborative learning. Internet and Higher Education, 26, 33-41. doi: 10.1016/j.iheduc.2015.04.003

Cheng, K. H., \& Tsai, C. C. (2016). The interaction of child-parent shared reading with an augmented reality (AR) picture book and parents' conceptions of AR learning. British Journal of Educational Technology, 47(1), $203-222$. doi: $10.1111 /$ bjet.12228

Park, S. B., Jung, J. J., \& You, E. (2015). Storytelling of collaborative learning system on augmented reality. In Camacho, D., Kin, S.-W., \& Trawinki, B. (Eds.), New trends in computational collective intelligence, series studies in computational intelligence, 572, 139-147. 
Hsieh, M.C. \& Lee, J.S. (2008). AR marker capacity increasing for kindergarten English learning. International Multiconference of Engineerings and Computer Scientists, 663-666.

Behzadan, A. H., Dong, S., \& Kamat, V. R. (2015). Augmented reality visualization: A review of civil infrastructure system applications. Advanced Engineering Informatics,29(2), 252-267.

doi:https://doi.org/10.1016/j.aei.2015.03.005

Liu, P.-H. E., \& Tsai, M.-K. (2013). Using augmented-reality-based mobile learning material in EFL English composition: An exploratory case study. British Journal of Educational Technology, 44(1):E1-E4.

doi:10.1111/j.1467-8535.2012.01302.x 